\title{
The Carbon Costs of In-Person Versus Virtual Medical Conferences for the Pharmaceutical Industry: Lessons from the Coronavirus Pandemic
}

\author{
William T. Gattrell ${ }^{1}$ Aurélie Barraux ${ }^{2} \cdot$ Sam Comley $^{3} \cdot$ Michael Whaley $^{4} \cdot$ Nicholas Lander $^{5}$
}

Accepted: 31 January 2022 / Published online: 26 February 2022

(c) The Author(s) 2022

\begin{abstract}
Background Many in-person congresses have shifted to a virtual format owing to coronavirus disease 2019 (COVID-19). We assessed carbon emissions savings associated with virtual attendance at international medical congresses for a mid-sized pharmaceutical company, to identify which aspects are driving the carbon cost.

Methods We assessed carbon emissions that were the responsibility of company attendees (including their guests) for the most attended congresses by employees (American Society of Clinical Oncology [ASCO], European Neuroendocrine Tumor Society [ENETS], European Society for Medical Oncology [ESMO], World Congress for NeuroRehabilitation [WCNR]). For in-person estimates, we considered travel, accommodation and congress attendance; for online estimates, we considered office and internet-related energy use. Emissions were defined using recognised data sources.

Results For 1723 anticipated in-person attendees, calculated total carbon emissions were 3,262,574 $\mathrm{kgCO}_{2 \mathrm{e}}$ (mean per inperson company attendee, $1894 \mathrm{kgCO}_{2 \mathrm{e}}$ : ASCO, 4172; ESMO, 1479; WCNR, 1153; ENETS, 1009). For context, the average UK resident's annual carbon footprint is $5600 \mathrm{kgCO}_{2 \mathrm{e}}$. Travel accounted for $91-96 \%$ of total emissions, mainly through long distance and business-class air travel. Calculated total carbon emissions associated with 1839 virtual attendees were 19,095 $\mathrm{kgCO}_{2 \mathrm{e}}$ (mean per virtual company attendee, $10.4 \mathrm{kgCO}_{2 \mathrm{e}}$; equivalent to approximately $0.3-1.1 \%$ of in-person attendance emissions across all four congresses assessed).

Conclusion Carbon emissions associated with virtual attendance were two orders of magnitude lower than for in-person attendance, and therefore the benefits of in-person attendance at medical congresses must be balanced against the carbon cost. Due diligence around who should attend and how they should travel to face-to-face meetings, and consideration of hybrid and domestic satellite options could be part of a balanced solution to reducing carbon emissions.
\end{abstract}

\section{Introduction}

Almost 20 years ago, Nature journal published a letter entitled "Virtual solution to carbon cost of conferences", which highlighted improvements in technology that could make virtual congresses 'more like real ones, without the flights' [1]. Since then, several reports and opinion pieces on this topic

William T. Gattrell

wgattrell@yahoo.co.uk

Ipsen, 102 Park Dr, Milton, Abingdon OX14 4RY, UK

2 Ipsen, Paris, France

3 Ipsen, Slough, UK

4 Ipsen, Cambridge, MA, USA

5 N Lander Consulting, Melbourne, VIC, Australia have been published [2-14], including a debate in the British Medical Journal on the merits and environmental impacts of international congresses $[2,3]$. This is perhaps not surprising given the scale of some international congresses and the need for international travel. However, despite these concerns, relatively few studies have quantified the carbon footprint of medical congresses [15]. An analysis of 4834 attendees at the 2019 annual congress of the American Society of Tropical Medicine and Hygiene reported that carbon emissions were equal to the total weekly carbon emissions of approximately 9366 average American households [16]. It has also been estimated that delegate travel to and from a single large academic congress can be responsible for generating carbon emissions equivalent to that of an entire city in a single week [17]. Other similar studies have also highlighted the large impact of medical congresses on carbon emissions [18-21]. 


\section{Key Points}

Faced with the coronavirus pandemic, medical congresses shifted from the traditional carbon-intensive inperson format to an online format in 2020, and this shift has afforded us the opportunity to assess the potential carbon savings associated with virtual congress attendance for a mid-sized pharmaceutical company. To the best of our knowledge, this is the first study to assess the carbon footprint associated with international congress attendance for a pharmaceutical company.

In our analysis, we found that the scale of the difference (two orders of magnitude) between in-person and virtual attendance was substantially bigger than expected, as was the dominance of attendee air travel, particularly when travelling business class. There is a clear incentive to assess carbon savings associated with a transition to a virtual or local platform, and a better understanding of the drivers of carbon emissions in this setting would help efforts to reduce the carbon footprint associated with medical congresses.

For the sake of global health, the benefits of attending international medical congresses in person must be balanced against the carbon cost. Everyone can play their part in reducing the carbon footprint: on a personal level, we should carefully consider who should attend and how we travel to face-to-face meetings; companies should consider introducing 'carbon budgets' for employees, and congresses should look at hybrid and domestic satellite options.

While the carbon-intensive nature of attending congresses stimulated debate before coronavirus disease 2019 (COVID19) [9], the pandemic has certainly sharpened this focus. Indeed, during the pandemic, government policies to restrict populations to their homes led to a fall in global daily carbon dioxide $\left(\mathrm{CO}_{2}\right)$ emissions of approximately $17 \%$ by early April 2020 compared with mean 2019 levels [22]. Almost one-half of this reduction was attributed to reduced transport use [22]. With these global restrictions on travel, many business sectors, including healthcare, had to evolve to adopt virtual ways of working, precipitating a shift from in-person to virtual attendance at international medical congresses. An analysis of 102 medical congresses scheduled to take place between March and December in 2020 showed that one-half switched to a virtual format and one-quarter were cancelled [23]. Interestingly, a study of one astronomy meeting reported that switching to a virtual format, necessitated by COVID-19, was associated with a 3000-fold reduction in emissions [24]. There is a clear incentive to assess carbon savings related to a transition to a virtual platform, and a better understanding of the drivers of carbon emissions in this setting would help efforts to reduce the carbon footprint associated with medical congresses.

Pharmaceutical companies have a substantial presence at international medical congresses and are therefore considerable carbon contributors. Indeed, researchers at McMaster University (Hamilton, ON, Canada) have suggested that overall the pharmaceutical industry is more carbon intensive than the automotive industry [25]. Some pharmaceutical companies have set ambitious goals to reduce their carbon emissions to become carbon neutral with respect to their direct scope 1 and 2 emissions, and also to work with their suppliers to reduce their scope 3 emissions [26, 27]. Understanding a company's carbon footprint associated with congress attendance can help towards reaching these goals. In this study, we present the findings of our assessment of savings in carbon emissions associated with virtual presence (versus in-person attendance) at the four international medical congresses in 2020 most attended by the staff and guests of a mid-sized pharmaceutical company.

\section{Methods}

\subsection{Study Design}

Ipsen is a global, mid-sized pharmaceutical company with headquarters in Paris and France, and approximately 5700 employees worldwide. We assessed savings in carbon emissions associated with attendance by employees and their guests at key international medical congresses in 2020 (from this point, employees and their guests will be described collectively as company attendees). Employees from pharmaceutical companies attend medical congresses for education, scientific exchange and networking opportunities.

We calculated theoretical in-person and virtual carbon emissions for the four congresses that were most attended in 2020 (total of 1723 in-person company attendees and 1839 virtual company attendees): the American Society of Clinical Oncology (ASCO), European Neuroendocrine Tumor Society (ENETS), European Society for Medical Oncology (ESMO), and World Congress for Neurorehabilitation (WCNR). All four congresses moved to a virtual format in 2020 but were originally scheduled to be hosted in Chicago (IL, USA), Barcelona (Spain), Madrid (Spain), and Lyon (France), respectively.

\subsection{Carbon Emissions}

We included in our analysis carbon emissions that were considered relevant or material to the overall carbon footprint of congress attendance. These are described in subsequent sections, and cover scope 2 and selected scope 3 emissions 
from the Greenhouse Gas Protocol 2011 [28]. Scope 2 covers indirect emissions from purchasing electricity, while scope 3 covers all other emissions occurring in the supply chain; scope 1 emissions (i.e., direct emissions from burning fossil fuels in company-controlled equipment) were not included because none were produced [28].

\subsection{Relevant Activities}

We considered only those activities that were the responsibility of company attendees, i.e. travel, office-related activities (computers and internet, lights and power, and heating, ventilation and air conditioning loads), and individuals' heat load. Those activities related to other attendees or the congress organisers were excluded from these analyses (Fig. 1).

\subsection{Boundaries and Assumptions: In-Person Congress Emissions}

\subsubsection{Attendees}

We based the total number of company attendees at in-person congresses and the home country for each person on booked (ENETS) or planned travel details before the congresses moved from a physical meeting to a virtual platform; we assumed that all attendees would depart from one location per country. For congresses for which travel and attendance had not been booked (ASCO, ESMO, and WCNR), company attendee numbers were based on 2019 attendance. Emissions related to the attendee's home were not included in the in-person analyses.

\subsubsection{Travel}

We assumed that home city transfers (travel from the attendee's home to the point of departure) were by taxi, with an average travel distance for each city based on the distance from the city centre to the airport or train station. Some airports, such as Hong Kong, have convenient high-speed rail links and the airports are far from the city. Home city transfers in Hong Kong were therefore modelled by train rather than by taxi. All other airports assumed the more conservative taxi option. We based taxi emissions on published data from the UK (BEIS Business Travel-Land data) and USA [29, 30], expressed as passenger-kilometres (p.km, defined
Fig. 1 Activities that contribute to the carbon footprint of in-person and virtual congresses by pharmaceutical company attendees and other responsible parties. Coloured activities are the responsibility of company attendees and were included in the main analysis. Greyed-out activities were not included in the analysis. HVAC heating, ventilation and air conditioning

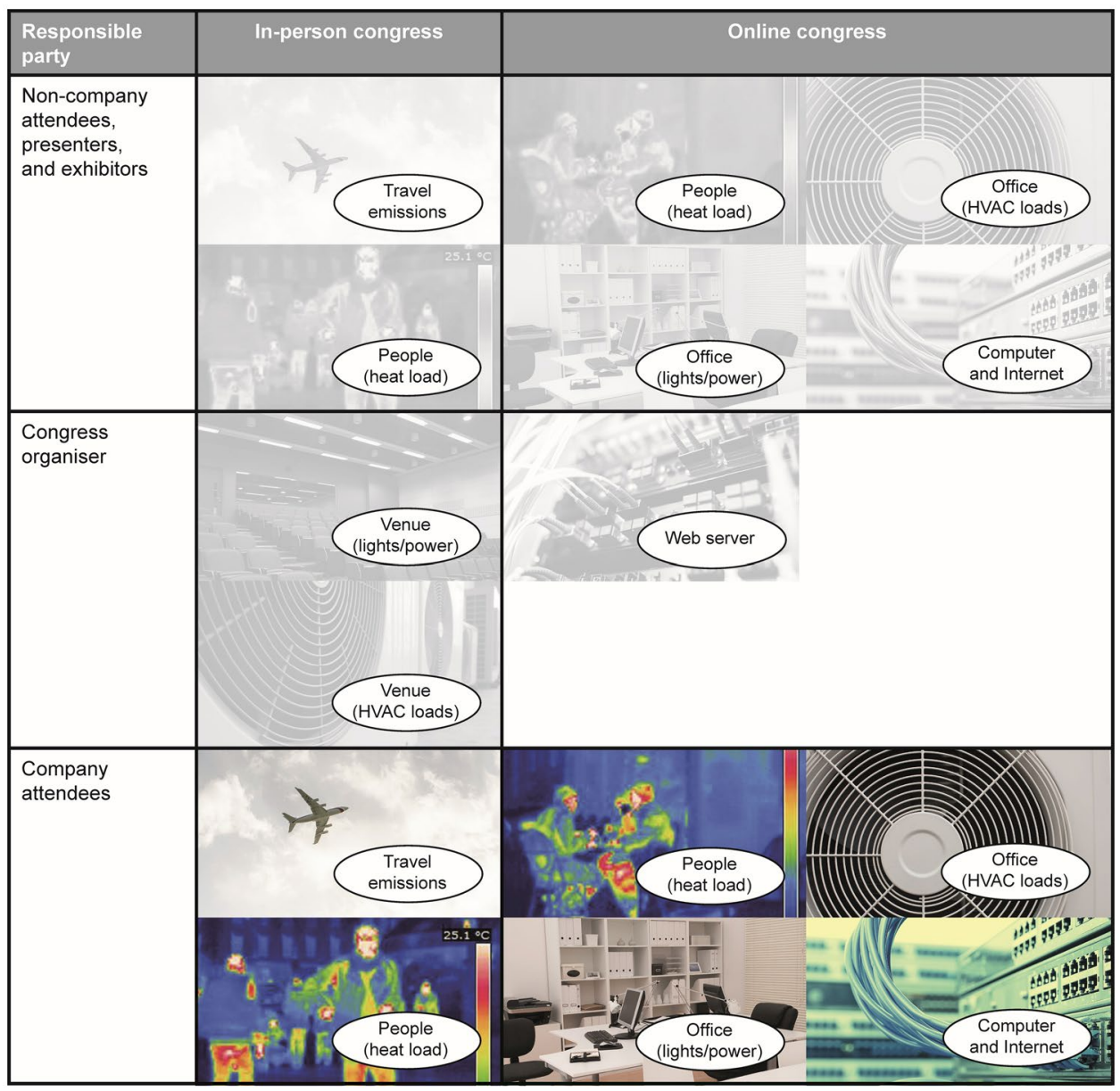


as the total number of kilometres travelled by all passengers). We excluded all emissions related to the normal running of the point of departure (i.e., the airport or train station) that were due only to company attendees (e.g., cooling loads) based on the assumption that they were immaterial (contributed $<1 \%$ of the total emissions). We also excluded other modes of transport.

We assumed that intercity travel to the congress was by commercial airlines for all attendees except those travelling from Barcelona to Madrid and from Paris to Lyon, which we assumed to be by domestic high-speed train. In line with the travel policy at the company, we assumed that international flights of $3700 \mathrm{~km}$ or over were business class and fights of under $3700 \mathrm{~km}$ were economy class. Premium economy and first-class travel were excluded. We based distances travelled on 'great circle' distances for flights and published distances for trains, and emissions on standard p.km rates [29, 31, 32]. We used standard rates of emissions per $\mathrm{km}$, which include baggage. As with departures, we excluded all emissions related to the point of arrival (airport or train station).

We assumed that transfers from the point of arrival to the hotel were by taxi; we excluded other modes of transport.

\subsubsection{Hotel Accommodation}

We based hotel selection on the original bookings before the congress moved to a virtual platform or on the hotels used in 2019. In cases of company attendees without historic bookings, it was assumed they would have booked hotels similar to those attendees with historic bookings; the same selection of hotels and in the same ratio across the different hotels. We based hotel emissions on published per room-night emissions using rates for the 'Upscale and Upper Upscale' market segment in each congress city [33].

\subsubsection{Congress Attendance}

Congress-venue emissions included cooling energy associated with company attendees' body heat load (assumed to be $150 \mathrm{~W}$ per person; sensible plus latent load). We estimated congress-venue emissions using the admittance method calculation with broad assumptions about the venue buildings (venues were assumed to be square, single story, with no windows, and total areas were based on published venue floor areas and numbers of attendees) and climate data for the city and month in which the congress was held. We considered other venue loads, such as lights and power, to be the responsibility of the venue, and the proportion of heating/cooling energy for non-company attendees to be their own responsibility. We based time spent at the congress venue on published programmes for European congresses: the ASCO programme was not summarised in one place and therefore we assumed that attendance time was $8 \mathrm{~h}$ per day. We excluded all other congress venue activities.

We excluded carbon emissions associated with food and drink on the basis that attendees would need to eat and drink irrespective of congress attendance.

\subsection{Boundaries and Assumptions: Virtual Congress Emissions}

For virtual congresses, we considered office or home energy loads for the room from which the company attendee joined the virtual congress. We based heating (assumed electric heating) and cooling loads for office rooms on an assumed room size and construction (assumed modern buildings), and on climate data from the relevant city using data from the American Society of Heating, Refrigerating and AirConditioning Engineers [34]. We based carbon emissions from energy consumption on national averages for electricity grid emissions factors [29, 35, 36]. Heating and cooling of home rooms from which company attendees joined a virtual congress were not modelled. We assumed the whole house would be heated/cooled if someone was working from home and not just the specific room they used as an office. Therefore, virtual congress attendance from home was considered to not incur additional heating/cooling.

Internet-related emissions included the company attendee's computer (laptop or desktop) and office/home modem/ router, the internet service provider in the attendee's home country, and transmission between the two. Internet emissions were based on research by the American Council for an Energy Efficient Economy [37]. As bandwidth requirements depend on quality (800 kbps for low quality video and 1500 kbps for high quality), an average of the two was taken. We assumed that data provision was made using cloud-based solutions (e.g. Zoom) rather than via local servers, with energy consumption measured in $\mathrm{kWh} / \mathrm{GB}$ transmitted. We based time spent online on congress programmes, minus scheduled breaks, multiplied by $50 \%$ to account for selective viewing because not all attendees will view/attend all parts of the congress (ASCO was based on $8 \mathrm{~h}$ per day multiplied by $50 \%)$. We excluded additional internet infrastructure because it is not possible to know the physical route that data will take between nodes.

See Online Resource 1 for additional boundaries and assumptions.

\subsection{Sources of Emission Factors}

The sources of data used in this study are summarised in Online Resource 2. 


\subsection{Statistical Analysis}

We assessed calculated carbon emissions using descriptive statistics. For perspective, we compared total carbon emissions with a UK resident's annual carbon footprint (based on territorial fossil fuel emissions) in 2018 of $5600 \mathrm{~kg} \mathrm{CO}_{2}$ equivalent $\left(\mathrm{kgCO}_{2 \mathrm{e}}\right)$ [38].

Several sensitivity analyses and a whole-congress analysis were also conducted (see Methods in Online Resource 1).

\subsection{Role of the Funding Source}

The sponsor was involved in the study design and the analysis and interpretation of results, as well as review of the manuscript.

\section{Results}

\subsection{In-Person Carbon Emissions}

In total, we included 1723 anticipated in-person company attendees in this analysis. We calculated total carbon emissions to be 3,262,574 $\mathrm{kgCO}_{2 \mathrm{e}}$ (Fig. 2a). Travel accounted for $91-96 \%$ of the total carbon emissions per congress, and intercity travel (particularly long-distance and business-class air travel) accounted for 90-94\% (Fig. 2a). Indeed, published emissions rates are 2.9-fold higher for long-haul businessclass flights $\left(0.4239 \mathrm{kgCO}_{2 \mathrm{e}}\right.$ per p.km) than for short-haul economy-class flights $\left(0.1462 \mathrm{kgCO}_{2 \mathrm{e}}\right.$ per p.km) [29]. In a sensitivity analysis, if company attendees modelled as having travelled by business-class flights had in fact travelled by economy-class flights, total air-travel emissions were reduced by approximately $50 \%$ for each congress (emissions $\left[\mathrm{kgCO}_{2 \mathrm{e}}\right]$ per attendee: ASCO, from 906 to 518; ENETS, from 3935 to 1466; ESMO, from 1337 to 672; WCNR, from 1084 to 532 ).

Hotel accommodation was the next largest contributor to total carbon emissions per congress, accounting for 4-9\%. Taxis and cooling of company attendees at the congress venue accounted for approximately $1 \%$ and $0.01 \%$, respectively, of total carbon emissions per congress. Even if the cooling loads were increased 100-fold (sensitivity analysis), the impact on total emissions was still $<1 \%$.

Carbon emissions per company attendee ranged from 1009 to $1479 \mathrm{kgCO}_{2 \mathrm{e}}$ for the European congresses, representing $18-26 \%$ of the average UK resident's annual carbon footprint (Fig. 2b). Considering intercontinental travel, emissions per company attendee at ASCO represented $75 \%$ of a UK resident's annual carbon footprint.

\subsubsection{Travel}

Of the four congresses examined, ASCO had the highest total carbon emissions $\left(1,664,787 \mathrm{kgCO}_{2 \mathrm{e}}\right)$, largely owing to the impact of intercontinental travel $\left(1,569,937 \mathrm{kgCO}_{2 \mathrm{e}}\right)$ [Fig. 2a]. For ASCO, p.km for intercity travel were up to 5.5 times higher (3,981,302 p.km) than for ENETS $(2,209,672$ p.km), ESMO (2,293,997 p.km), and WCNR (722,219 p.km).

Intercity travel emissions were lowest for WCNR, to which a substantial proportion of company attendees
Fig. 2 Total carbon emissions associated with in-person congress attendance by $\mathbf{a}$ contributing activity and $\mathbf{b}$ congress, for pharmaceutical company attendees. $*$ The average annual carbon footprint of a UK resident is $5600 \mathrm{kgCO}_{2 \mathrm{e}}$ [38]. Values are subject to rounding. ASCO American Society of Clinical Oncology, ENETS European Neuroendocrine Tumor Society, ESMO European Society for Medical Oncology, $\mathrm{kgCO}$, kilograms of carbon dioxide equivalent, WCNR World Congress for Neurorehabilitation a

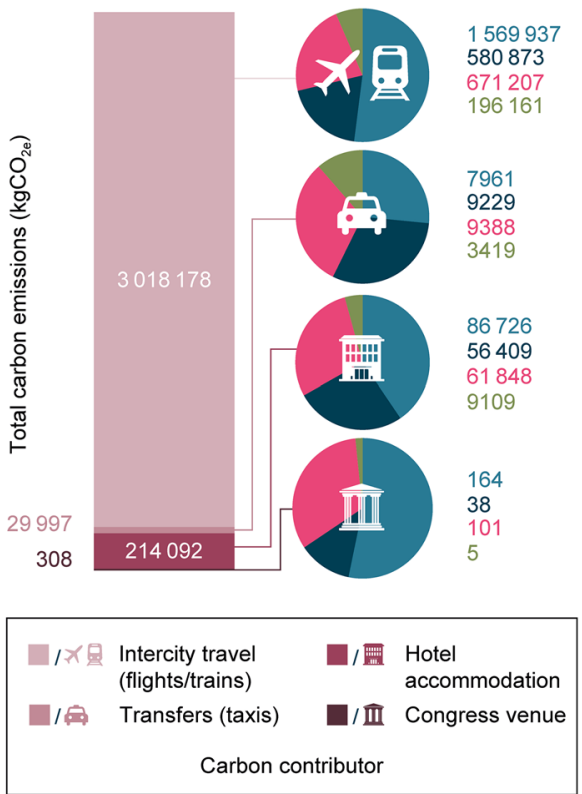

b

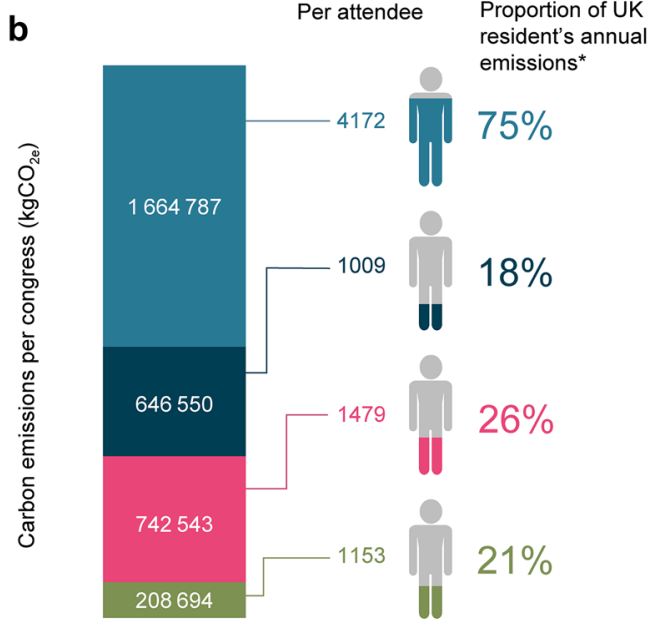


(76/181) were modelled as travelling by train (Fig. 3a). Most intercity flights to European congresses were economy class because most company attendees lived in Europe (Fig. 3a); however, the total distances travelled by business class were greater than those travelled by economy class for ESMO and WCNR (Fig. 3b). At ENETS, distances travelled were lower for business class than for economy class. However, because of the substantial carbon emissions associated with this form of transport, business-class travel was associated with the highest levels of carbon emissions for all three European congresses (Fig. 3c). Overall, carbon emissions per p.km travelled were similar across all three European congresses (range 0.263-0.293 $\mathrm{kgCO}_{2 \mathrm{e}} / \mathrm{p} . \mathrm{km}$ ) (Fig. 3c).
Emissions rates $\left(\mathrm{kgCO}_{2 \mathrm{e}}\right.$ per attendee) associated with taxis were similar across all four congresses (Fig. 4a). Distances (p.km) travelled by taxi for WCNR were approximately 2.5 times lower than for other congresses but this was largely owing to fewer company attendees. Emissions per attendee for intracity travel were about the same for all congresses, except ENETS for which the majority of company attendees were assumed to have walked to the venue.

\subsubsection{Hotel Accommodation}

Total carbon emissions associated with hotel accommodation were higher at ASCO (217.4 $\mathrm{kgCO}_{2 \mathrm{e}}$ per attendee) than at the European congresses (50.3-123.2 $\mathrm{kgCO}_{2 \mathrm{e}}$ per
Fig. 3 Intercity travel associated with in-person attendance at European congresses by a number of attendees, $\mathbf{b}$ distance travelled, and $\mathbf{c}$ carbon emissions, for pharmaceutical company attendees. Carbon emissions from train travel are so low that they are not always clearly visible on the scale in the graph. Electricity grid emissions for Chicago $\left(0.390 \mathrm{kgCO}_{2 \mathrm{e}}\right.$ / $\mathrm{kWh}$ ) are double those for Barcelona and Madrid (0.220 $\mathrm{kgCO}_{2 \mathrm{e}} / \mathrm{kWh}$ ). The orange line depicts an average across all travel types. ENETS European Neuroendocrine Tumor Society, ESMO European Society for Medical Oncology, $\mathrm{kgCO}_{2 e}$ kilograms of carbon dioxide equivalent, $p . \mathrm{km}$ passenger-kilometres, WCNR World Congress for Neurorehabilitation
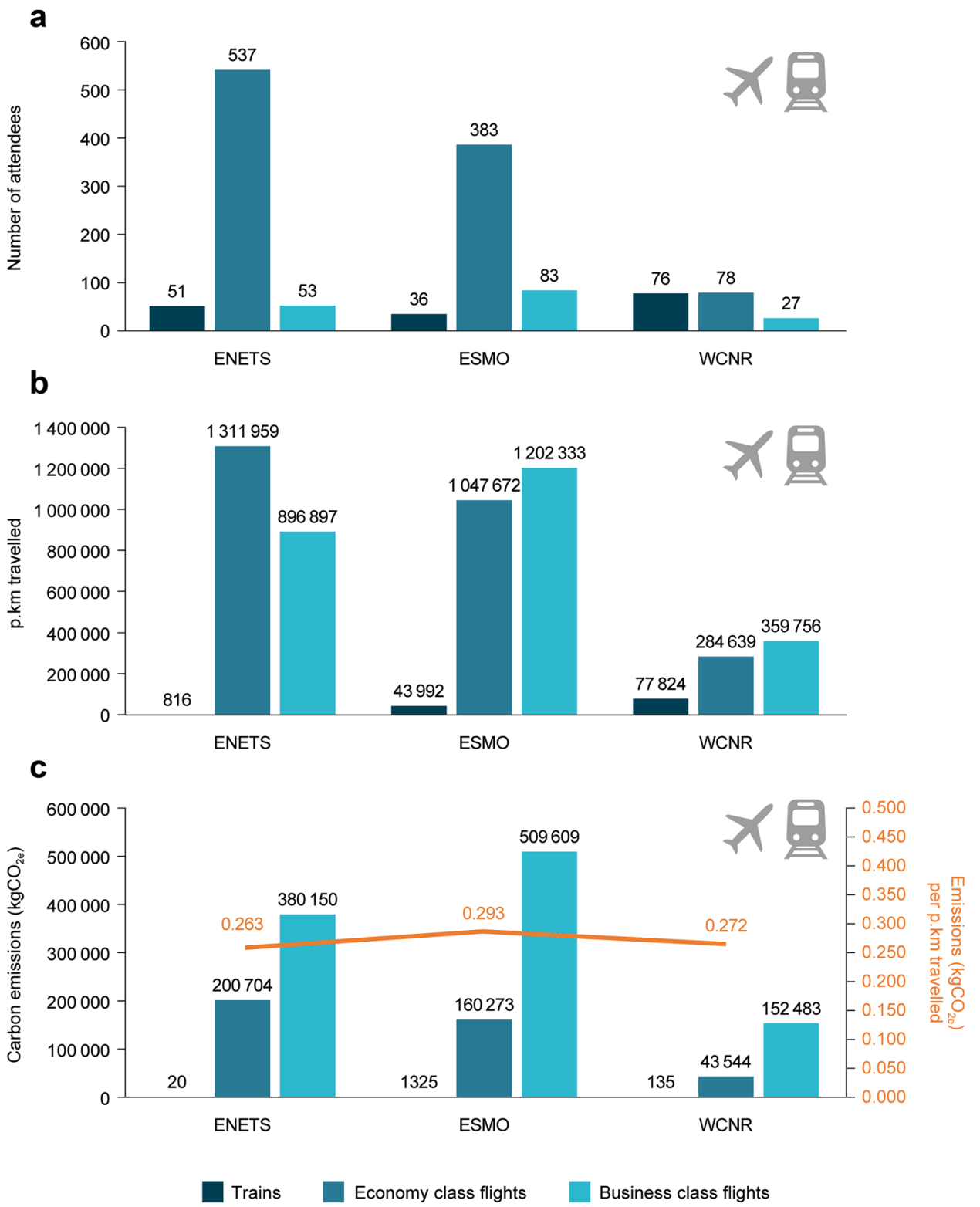
attendee), owing to the fact that hotels in Chicago are typically more carbon intensive than those in Europe (Fig. 2a). Normalised hotel emissions per room-night, based on differences in electricity grid efficiencies between cities, reinforced the difference above, with hotel emissions at $7.2 \mathrm{kgCO}_{2 \mathrm{e}}$ per room-night in France and $17.6 \mathrm{kgCO}_{2 \mathrm{e}}$ per room-night in Spain, compared with $36.2 \mathrm{kgCO}_{2 \mathrm{e}}$ per roomnight in the US (Fig. 4b).

\subsubsection{Congress Attendance}

Emissions rates $\left(\mathrm{kgCO}_{2 \mathrm{e}}\right.$ per $\left.\mathrm{kWh}\right)$ associated with cooling loads at congress venues varied across congresses, with up to a tenfold difference between the highest (ASCO, 0.390) and lowest values (WCNR, 0.039) [Fig. 4c]. These differences were due to the numbers of company attendees and local electricity grid emissions factors.

\subsection{Virtual Carbon Emissions}

In total, there were 1839 virtual company attendees. We calculated total carbon emissions to be $19,095 \mathrm{kgCO}_{2 \mathrm{e}}$ (Fig. 5a). Internet energy use accounted for $93-94 \%$ of the total carbon emissions per congress, with office energy accounting for the remaining emissions.

Carbon emissions per company attendee ranged from 7 to $14 \mathrm{kgCO}_{2 \mathrm{e}}$ across all four congresses, representing $0.12-0.25 \%$ of the average UK resident's annual carbon footprint (Fig. 5b). Emissions per attendee were driven largely by the volume of content delivered via the congress platform (i.e. the total number of hours delivered, evaluated using the programmes for each congress). In a sensitivity analysis, changing virtual congresses from a high bandwidth $(24,511$ $\left.\mathrm{kgCO}_{2 \mathrm{e}}\right)$ to a low bandwidth $\left(13,680 \mathrm{kgCO}_{2 \mathrm{e}}\right)$ would result in a $44 \%$ reduction in carbon emissions. While low bandwidth
Fig. 4 Carbon emissions associated with in-person congress attendance by a taxi, $\mathbf{b}$ hotel accommodation, and $\mathbf{c}$ congress venue, for pharmaceutical company attendees. Distance travelled by taxis for ENETS in panel a included 8230 p.km by shuttle bus. ASCO American Society of Clinical Oncology, ENETS European Neuroendocrine Tumor Society, ESMO European Society for Medical Oncology, $\mathrm{kgCO}_{2 e}$ kilograms of carbon dioxide equivalent, $p . \mathrm{km}$ passenger-kilometres, WCNR World Congress for Neurorehabilitation
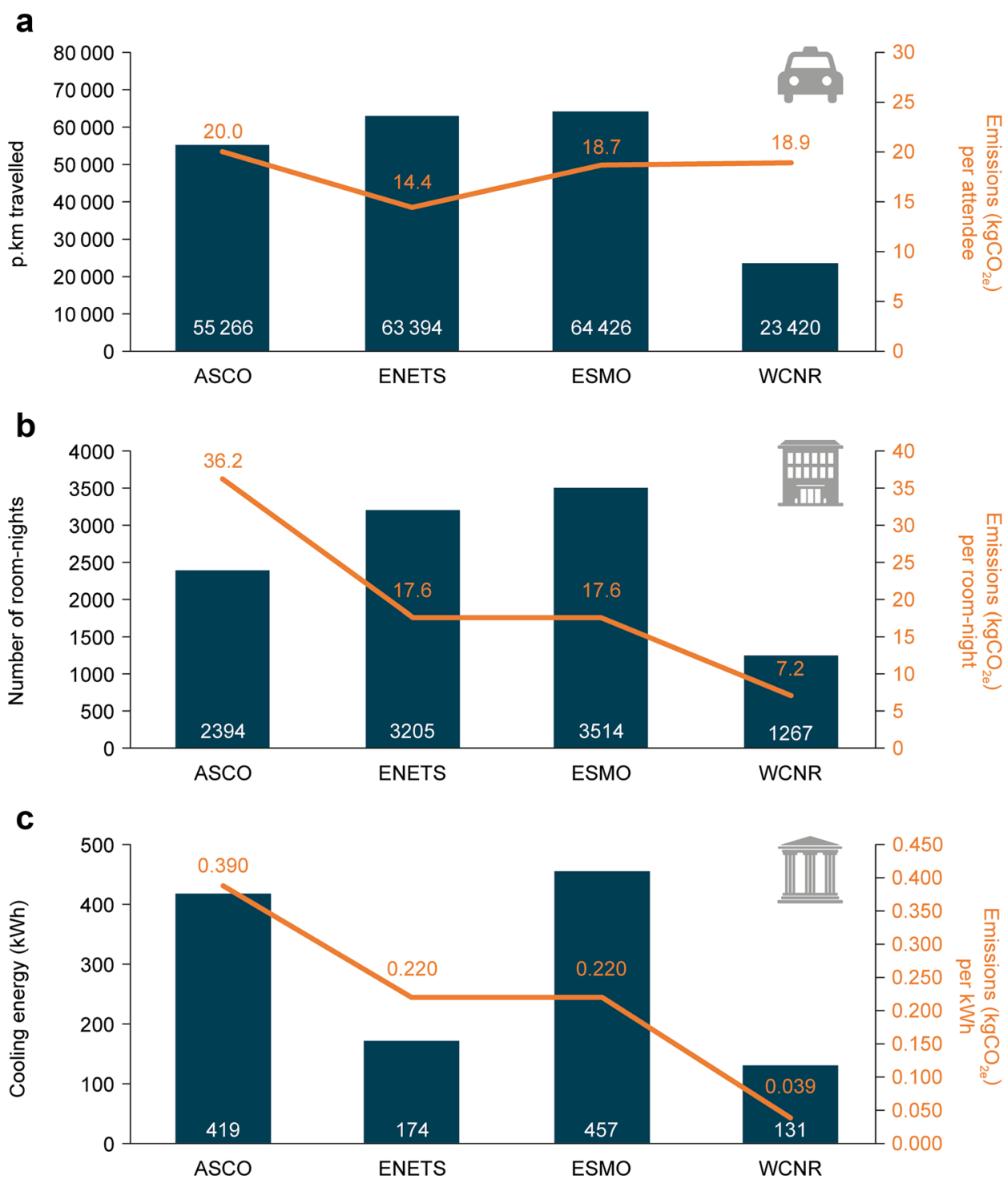
Fig. 5 Total carbon emissions associated with virtual congress attendance by a contributing activity and $\mathbf{b}$ congress, for pharmaceutical company attendees. *The average annual carbon footprint of a UK resident is $5600 \mathrm{kgCO}_{2 \mathrm{e}}$ [38]. Values are subject to rounding. ASCO American Society of Clinical Oncology, ENETS European Neuroendocrine Tumor Society, ESMO European Society for Medical Oncology, $\mathrm{kgCO}_{2 e}$ kilograms of carbon dioxide equivalent, WCNR World Congress for Neurorehabilitation

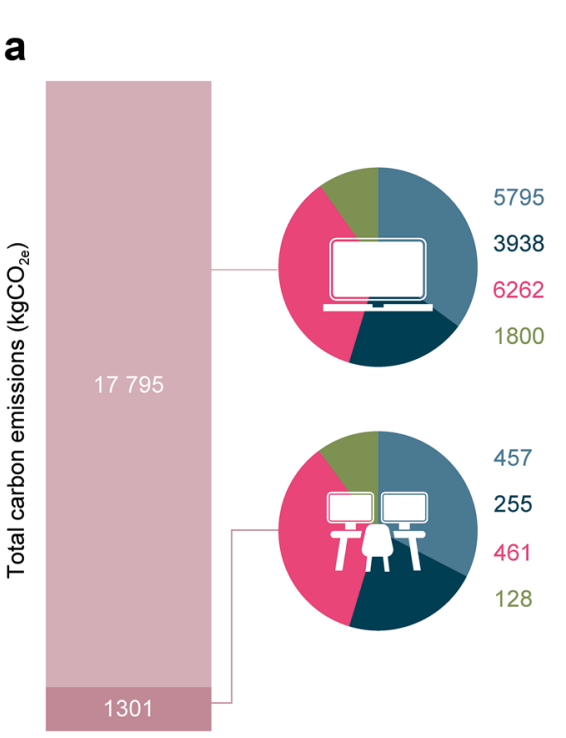

b

Per attendee

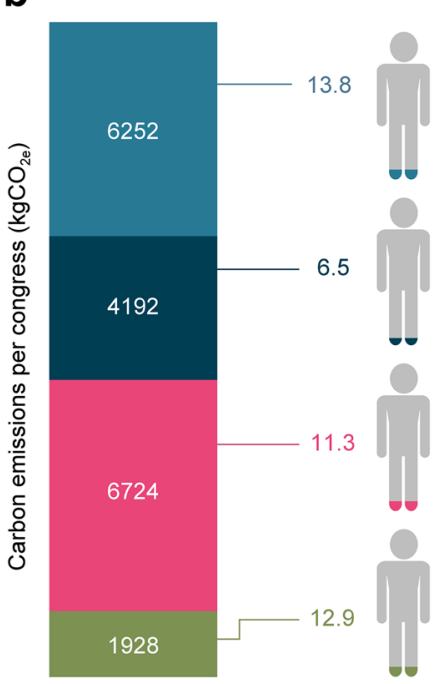
resident's annual emissions*

$0.25 \%$

$0.12 \%$

$0.20 \%$

\section{$0.23 \%$}

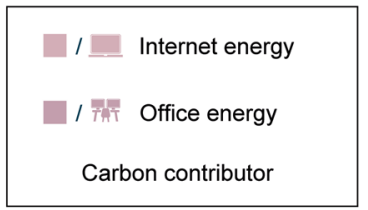

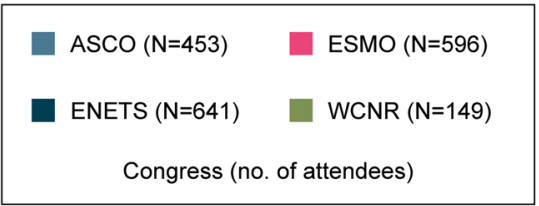

presents a carbon saving compared with high bandwidth, the impact may not be worth the drop in transmission quality.

\subsection{In-Person versus Virtual Congress Attendance}

Virtual congress attendance was associated with substantially lower carbon emissions per company attendee (mean
$10.4 \mathrm{kgCO}_{2 \mathrm{e}}$ ) than in-person attendance (mean $1894 \mathrm{kgCO}_{2 \mathrm{e}}$ ) (Fig. 6). Per-attendee emissions associated with virtual attendance accounted for approximately $1 \%$ of those associated with in-person attendance across all four congresses (ASCO, 0.3\%; ENETS, 0.6\%; ESMO, 0.8\%; WCNR, 1.1\%). Per-person taxi emissions alone (mean $17.4 \mathrm{kgCO}_{2 \mathrm{e}}$ ) were similar to the total per-person carbon emissions associated
Fig. 6 Comparison between in-person and virtual congress emissions for pharmaceutical company attendees. *The average annual carbon footprint of a UK resident is $5600 \mathrm{kgCO}_{2 \mathrm{e}}$ [38]. Data are averaged across all four congresses. Values are subject to rounding. Circle diameter depicts average per-person carbon emissions. $\mathrm{kgCO}_{2 e}$ kilograms of carbon dioxide equivalent
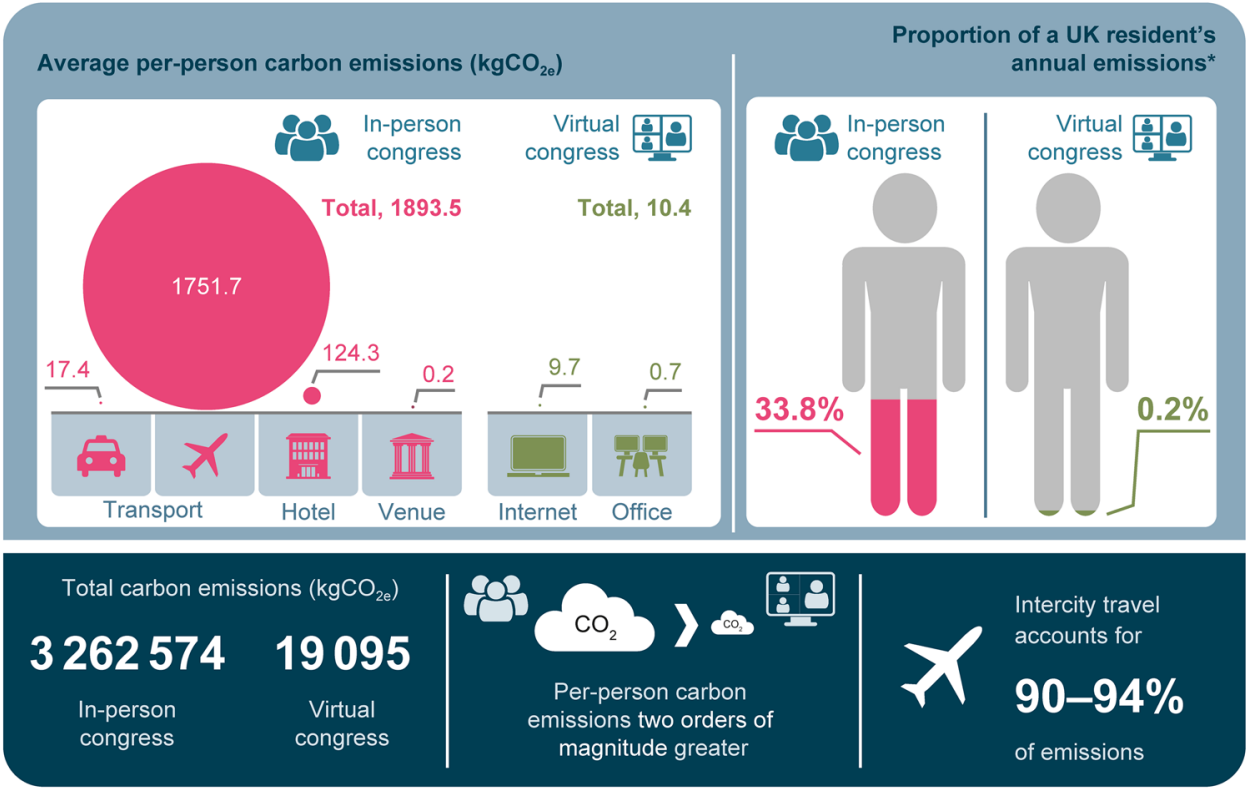
with virtual attendance. A total of $3,243,478 \mathrm{kgCO}_{2 \mathrm{e}}$ was saved by company attendees moving from in-person to virtual attendance at just these four congresses.

In a separate whole-congress analysis, with emissions considered for 67,300 anticipated attendees across all four congresses, we calculated whole-congress rough order of magnitude (ROM) emissions to be $127,515,000 \mathrm{kgCO}_{2 \mathrm{e}}$ for in-person attendance and $640,700 \mathrm{kgCO}_{2 \mathrm{e}}$ for virtual attendance (Online Resource 3). For virtual attendance, ROM emissions per attendee (mean $9.5 \mathrm{kgCO} 2 \mathrm{e}$ ) were equivalent to $0.5 \%$ of those for in-person attendance (Online Resource 3 ). The carbon footprint of holding the ASCO, ENETS, ESMO, and WCNR congresses in person is equivalent to the yearly emissions for $14,448,541,6766$, and 1014 UK residents, respectively. The carbon footprint of holding these congresses virtually is equivalent to the yearly emissions for $89,1,22$, and 2 UK residents, respectively. Similar to the main analysis of company attendees, the main driver of in-person emissions was air travel. The main driver of virtual emissions was webhosting, accounting for 71-88\% of the total ROM emissions. If green webhosting (assumes a zero-carbon footprint) was assumed, we calculated wholecongress ROM emissions for virtual attendance to be 94,350 $\mathrm{kgCO}_{2 \mathrm{e}}$, representing an $85 \%$ reduction.

\section{Discussion}

This study assessed the carbon footprint associated with international congress attendance for a mid-sized pharmaceutical company. The results indicate that per-person carbon emissions for in-person attendance were two orders of magnitude greater than those for virtual attendance. Although we anticipated higher emissions levels with in-person attendance, the scale of difference was unexpected. Considering emissions from transport, hotels, and congress venues, we calculated total carbon emissions to be $3,262,574 \mathrm{kgCO}_{2 \mathrm{e}}$ (mean $1894 \mathrm{kgCO}_{2 \mathrm{e}}$ per company attendee) for traditional inperson attendance. Travel dominated emissions (91-96\%), mainly through long-distance and business-class flights, with sensitivity analyses showing that air-travel emissions could be halved if economy-class rather than business-class flights were used. In contrast, total carbon emissions associated with virtual attendance were $19,095 \mathrm{kgCO}_{2 \mathrm{e}}$ (mean $10.4 \mathrm{kgCO}_{2 \mathrm{e}}$ per company attendee); internet energy use was the main emissions contributor (93-94\%), with a sensitivity analysis showing that this depends on the bandwidth used. A surprising observation was that the carbon cost of simply taking taxis to and from the airport and between the hotel and congress venue was greater than that of attending an entire virtual congress. To add some perspective to these emissions values, we observed that in-person attendance at just one European congress was equivalent to between one-fifth and one-quarter of an average UK resident's annual carbon footprint in 2018 (based on 2019 data for territorial fossil fuel emissions) [38]; this rose to $75 \%$ for a transatlantic congress. Many company attendees travel to more than one congress every year.

Published studies assessing the carbon footprint of congresses are limited. The estimated per-person emissions associated with attendance at ASCO have previously been reported as $1060 \mathrm{~kg}$ of $\mathrm{CO}_{2}$ [39], which is around one-half of that reported in the present study. That this previous estimate was based only on return flights to Chicago for the three authors of the report (two from Canada and one from New Zealand), may explain the difference compared with the present study. One study that compared the in-person (travel emissions) and virtual attendance (network-, laptopand video conferencing-related emissions) of an astronomy meeting reported a difference of three orders of magnitude [24], which is even greater than the difference in the current analysis.

Switching to virtual attendance has carbon-saving potential for academic attendees as well as pharmaceutical company attendees, especially graduate students for whom in-person attendance represents $35 \%$ of the carbon footprint of their $\mathrm{PhD}$ [40]. A study of the carbon footprint (assessed according to scope 1, 2 and 3 of the Greenhouse Gas Protocol 2011) of a mid-sized UK university during the COVID-19 lockdown (April-June 2020) showed an almost $30 \%$ reduction in carbon emissions compared with the same period in previous years; emissions were 2140 tonnes of $\mathrm{CO}_{2}$ in 2019 compared with 1521 in 2020 [41]. The study also highlighted that although carbon savings were made, online teaching and learning was carbon intensive, equalling the carbon footprint of staff and student commutes during the pre-lockdown period.

In the current study, the whole-congress analysis which considered all anticipated attendees at the four congresses, estimated total carbon emissions to be $127,515,000 \mathrm{kgCO}_{2 \mathrm{e}}$ for in-person attendance and $640,700 \mathrm{kgCO}_{2 \mathrm{e}}$ for virtual attendance. The latter assumes that webhosting was not carbon neutral and green webhosting could further reduce whole-congress emissions for virtual attendance by $85 \%$. As well as carbon savings, virtual congresses have several other benefits. In our experience, virtual congresses provide a quick and user-friendly platform for disseminating scientific findings at a much lower cost than traditional in-person congresses. Access to congress sessions is also greater with virtual attendance because individuals can potentially attend one session live and later view a recorded parallel session, albeit congress-dependent. The convenience (and reduced costs) of attending virtually may also facilitate more diverse participation in medical congresses. However, there are anecdotal reports of 'virtual congress fatigue' and attendance for only a low proportion 
of a virtual meeting, perhaps owing to global time-zone scheduling conflicts and/or distraction by everyday work [42]. Greater volumes of data can be presented virtually than in person, but there is a fine balance between quantity and quality and a risk of overwhelming attendees. The virtual format is also limited compared with the in-person format in relation to aspects that are often considered to be the most important reasons for attending any congress: information exchange, networking, interdisciplinary discussions, meeting with experts, inspiration, acquiring serendipitous knowledge, full immersion in science, and professional development.

Prior to the COVID-19 pandemic, few medical congresses had made use of virtual platforms, possibly owing to current technology limitations, although some had piloted virtual presenters [7]. ESMO and ASCO have now implemented freely available virtual plenaries, which are monthly presentations of selected clinical trial data. These plenaries help to disseminate findings quicker than annual meetings. Medical congresses may continue to adopt the virtual model or evolve a hybrid model [43]. In a survey of over 900 Nature journal readers, $74 \%$ thought that scientific congresses should continue to be virtual or have a virtual element after the pandemic ends [42]. A hybrid model has the potential to combine the best of both formats; in-person attendees can make new serendipitous connections and exchange knowledge but those unable to travel can still attend and benefit from the information on offer. Although the full impact of COVID-19 on the future of medical congresses is still to be determined, the short-term reduction in travel and associated carbon savings will certainly help to reduce air pollution and tackle the ongoing climate crisis. Like all international companies, pharmaceutical companies are facing up to their responsibilities on climate change. For example, Ipsen has the stated goal of becoming carbon neutral by 2030 through reductions in scope 1,2, and 3 emissions. Novartis has recently announced that, in many cases, employees will be able to choose where they work [44]; however, the extent of the benefits of home-working on carbon emissions remains to be established [45].

To the best of our knowledge, this is the first study to assess the carbon footprint associated with international congress attendance for a mid-sized pharmaceutical company. A technical strength of this study is that emissions factors, such as grid electricity and UK/European travel, were based on robust data (emissions factors for transport were based on figures from a few countries, mainly the UK and France, and applied to other countries; loading factors for aircraft were based on UK figures only). Within the scope of the current study, applying such robust data is appropriate given the paucity of country-specific emissions data. Although emissions from hotels were based on a limited number of studies, they were checked against manual calculations. Limitations of the study include assumptions around congress attendance; the use of hotel emissions based on 2019 values; exclusion of factors such as food; and the fact that emissions from venues were based on the manual admittance method and assumed heating, ventilation, and air conditioning efficiencies. Finally, internet emissions associated with virtual attendance were underestimated owing to the exclusion of internet architecture as per the boundaries and assumptions outlined in the Methods, section 2.5.

Based on our findings, we have several immediate recommendations for reducing the carbon footprint of medical congress attendance: have fewer face-to-face meetings with more virtual/hybrid events; develop domestic satellite congress models; undertake due diligence on who needs to attend; introduce carbon budgets per employee; minimise air travel, particularly by business class; and use less carbon-intensive modes of transport. These are in line with recommendations from the American Thoracic Society for reducing the carbon footprint of their future annual meetings [46]. Purchasing carbon offsets was another recommendation of the American Thoracic Society [46]. There are several options to ensure that virtual attendance remains a feasible alternative or complement to in-person attendance, such as linking facilitators at congresses with virtual expert meetings during or after congresses, developing targeted and virtual learning sessions that can be complementary to primary presentations, and soliciting key opinion leaders to facilitate more in-depth meetings with interested attendees.

\section{Conclusion}

In our analysis of a mid-sized pharmaceutical company's carbon footprint associated with medical congress attendance, we found that the scale of the difference (two orders of magnitude) between in-person and virtual attendance was bigger than expected, as was the dominance of air travel on carbon emissions, particularly when travelling business class. For the sake of global health, the benefits of attending international medical congresses in person must be balanced against the carbon cost. Due diligence around who should attend and how they should travel to face-to-face meetings, and consideration of both hybrid and domestic satellite options could be part of a balanced solution to reducing carbon emissions.

Supplementary Information The online version contains supplementary material available at https://doi.org/10.1007/s40290-022-00421-3.

Acknowledgements The authors thank Dr. David Gothard of Oxford PharmaGenesis, Oxford, UK, for providing medical writing support, which was sponsored by Ipsen, in accordance with Good Publication Practice (GPP3) guidelines. 


\section{Declarations}

Funding This work was supported by Ipsen. The sponsor was involved in the study design, analysis, and interpretation, as well as review of the manuscript. The open access fee was paid by Ipsen.

Conflict of interest WTG, AB, SC and MW are full-time employees of Ipsen. NL works part-time at $\mathrm{N}$ Lander Consulting and received funding for this analysis from Ipsen.

Ethics approval Not applicable.

Consent to participate Not applicable.

Consent for publication Not applicable.

Availability of data and material The data underlying the results presented here are available from the corresponding author upon request.

Code availability Not applicable.

Author contributions WTG participated in study conception and design, data analysis, drafting the manuscript, critical review of the manuscript and revising the manuscript. $\mathrm{AB}, \mathrm{SC}$ and $\mathrm{MW}$ participated in study design, data analysis, drafting the manuscript, critical review of the manuscript and revising the manuscript. NL participated in study design, data collection, data analysis, drafting the manuscript, critical review of the manuscript and revising the manuscript. All authors read and approved the final submitted manuscript and agree to be accountable for the presented work.

Open Access This article is licensed under a Creative Commons Attribution-NonCommercial 4.0 International License, which permits any non-commercial use, sharing, adaptation, distribution and reproduction in any medium or format, as long as you give appropriate credit to the original author(s) and the source, provide a link to the Creative Commons licence, and indicate if changes were made. The images or other third party material in this article are included in the article's Creative Commons licence, unless indicated otherwise in a credit line to the material. If material is not included in the article's Creative Commons licence and your intended use is not permitted by statutory regulation or exceeds the permitted use, you will need to obtain permission directly from the copyright holder. To view a copy of this licence, visit http://creativecommons.org/licenses/by-nc/4.0/.

\section{References}

1. Reay DS. Virtual solution to carbon cost of conferences. Nature. 2003;424(6946):251.

2. Green M. Are international medical conferences an outdated luxury the planet can't afford? Yes. BMJ. 2008;336(7659):1466.

3. Drife JO. Are international medical conferences an outdated luxury the planet can't afford? No. BMJ. 2008;336(7659):1467.

4. Geitmann A. Travel less. Make it worthwhile. Cell. 2020;182(4):790-3.

5. Guterman L. Seeing green in conference season. Cell. 2009;137(7):1169-71.

6. Zotova O, Pétrin-Desrosiers C, Gopfert A, Van Hove M. Carbon-neutral medical conferences should be the norm. Lancet Planet Health. 2020;4(2):e48-50.
7. Roberts I, Godlee F. Reducing the carbon footprint of medical conferences. BMJ. 2007;334(7589):324-5.

8. Künzli N, Ragettli MS, Röösli M. The vision of a green(er) scientific conference. Environ Health Perspect. 2013;121(8):A236-7.

9. Govia I, Guell C, Unwin N, Wadende P. Air travel for global health: flying in the face of sustainable development? Lancet. 2019;394(10211):1786-8.

10. We need greener conferences. Nat Microbiol. 2019;4(9):1425. https://doi.org/10.1038/s41564-019-0554-y.

11. Counsell CWW, Elmer F, Lang JC. Shifting away from the business-as-usual approach to research conferences. Biol Open. 2020;9(10):bio056705.

12. Spinellis D, Louridas P. The carbon footprint of conference papers. PLoS ONE. 2013;8(6):e66508.

13. Hoyer KG, Naess P. Conference tourism: a problem for the environment, as well as for research? J Sustain Tour. 2010;9(6):451-70.

14. Nevins J. Academic jet-setting in a time of climate destabilization: ecological privilege and professional geographic travel. Prof Geogr. 2013;66(2):298-310.

15. Storz MA. Medical conferences and climate change mitigation: challenges, opportunities, and omissions. J Occup Environ Med. 2019;61(10):e434-7.

16. Bousema T, Selvaraj P, Djimde AA, Yakar D, Hagedorn B, Pratt A, et al. Reducing the carbon footprint of academic conferences: the example of the American Society of Tropical Medicine and Hygiene. Am J Trop Med Hyg. 2020;103(5):1758-61.

17. Klöwer M, Hopkins D, Allen M, Higham J. An analysis of ways to decarbonize conference travel after COVID-19. Nature. 2020;583(7816):356-9.

18. Yakar D, Kwee TC. Carbon footprint of the RSNA annual meeting. Eur J Radiol. 2020;125:108869.

19. Wortzel JR, Stashevsky A, Wortzel JD, Mark B, Lewis J, Haase E. Estimation of the carbon footprint associated with attendees of the American Psychiatric Association Annual Meeting. JAMA Netw Open. 2021;4(1):e2035641.

20. Fois M, Cuena-Lombraña A, Fristoe T, Fenu G, Bacchetta G. Reconsidering alternative transportation systems to reach academic conferences and to convey an example to reduce greenhouse gas emissions. Hist Philos Life Sci. 2016;38(4):25.

21. Callister ME, Griffiths MJ. The carbon footprint of the American Thoracic Society meeting. Am J Respir Crit Care Med. 2007; 175(4):417.

22. Le Quéré C, Jackson RB, Jones MW, Smith AJP, Abernethy S, Andrew RM, et al. Temporary reduction in daily global $\mathrm{CO}_{2}$ emissions during the COVID-19 forced confinement. Nat Clim Change. 2020;10:647-53.

23. Philippon V. Impact of COVID-19 pandemic on medical congresses [poster]. Presented at the International Society for Medical Publication Professionals (ISMPP) Europe 2021 conference.

24. Burtscher L, Barret D, Borkar AP, Grinberg V, Jahnke K, Kendrew $\mathrm{S}$, et al. The carbon footprint of large astronomy meetings. Nat Astron. 2020;4:823-5.

25. Belkhir L, Elmeligi A. Carbon footprint of the global pharmaceutical industry and relative impact of its major players. J Clean Prod. 2019;214:185-94.

26. AstraZeneca's 'Ambition Zero Carbon' strategy to eliminate emissions by 2025 and be carbon negative across the entire value chain by 2030 . AstraZeneca Press Release. 22 January 2020. https:// www.astrazeneca.com/content/astraz/media-centre/press-releases/ 2020/astrazenecas-ambition-zero-carbon-strategy-to-eliminateemissions-by-2025-and-be-carbon-negative-across-the-entirevalue-chain-by-2030-22012020.html. Accessed 8 June 2021. 
27. Commitment to Carbon Neutrality at Takeda. Takeda Corporate Responsibility. https://www.takeda.com/corporate-responsibi lity/environment/commitment-to-carbon-neutrality-at-takeda/. Accessed 8 June 2021.

28. Greenhouse Gas Protocol. Corporate Value Chain (Scope 3) Accounting and Reporting Standard. 2011. https://ghgprotocol. org/standards/scope-3-standard. Accessed 6 Jan 2022.

29. BEIS. Government greenhouse gas conversion factors for company reporting - methodology paper for conversion factors. 2020. https://assets.publishing.service.gov.uk/government/uploads/ system/uploads/attachment_data/file/901692/conversion-facto rs-2020-methodology.pdf. Accessed Sept 2020.

30. EPA. Emission factors for greenhouse gas inventories: US Environmental Protection Agency. 2020. https://www.epa.gov/sites/ production/files/2018-03/documents/emission-factors_mar_ 2018_0.pdf. Accessed Sept 2020.

31. Renfe. Sustainable Transport. 2020. https://www.renfe.com/es/en/ renfegroup/sustainable-transport/emissions-reduction. Accessed Sept 2020.

32. SNCF. Greenhouse gases information for transport servicesgeneral methodology; 1. Calculation methodology. 2020. https:// medias.sncf.com/sncfcom/rse/General-method_infoGHG.pdf. Accessed Sept 2020.

33. Ricaurte E, Jagarajan R. Benchmarking Index 2019: carbon, energy, and water. Cornell Hospitality Report. 2019. https://schol arship.sha.cornell.edu/chrpubs/266. Accessed Sept 2020.

34. ASHRAE. ASHRAE Climatic design conditions 2009/2013/2017. 2017. http://ashrae-meteo.info/v2.0/. Accessed Sept 2020

35. Carbon Footprint Ltd. Carbon footprint country specific electricity grid greenhouse gas emission factor. Last updated: July 2020. https://www.carbonfootprint.com/docs/2020_07_emissions_facto rs_sources_for_2020_electricity_v1_3.pdf. Accessed Sept 2020.

36. International Energy Agency. $\mathrm{CO}_{2}$ emissions from fuel combustion (2019 edition). 2019. https://iea.blob.core.windows.net/ assets/eb3b2e8d-28e0-47fd-a8ba-160f7ed42bc3/CO2_Emiss
ions_from_Fuel_Combustion_2019_Highlights.pdf. Accessed Sept 2020

37. Costernaro D, Duer A. The megawatts behind your megabytes: going from data-center to desktop. ACEEE summer study proceedings. American Council for an Energy Efficient Economy. 2012. http://www.aceee.org/files/proceedings/2012/data/papers/ 0193-000409.pdf. Accessed Sept 2020.

38. Global Carbon Atlas Project. Global Carbon Atlas. 2018. http:// www.globalcarbonatlas.org/en/CO2-emissions. Accessed Sept 2020.

39. Jacobs C, Joy AA, Clemons M. Will oncologists applaud the Paris Accord? Time to rethink global mega-conferences. Curr Oncol. 2016;23(4):223-4.

40. Achten WMJ, Almeida J, Muys B. Carbon footprint of science: more than flying. Ecol Indic. 2013;34:352-5.

41. Filimonau V, Archer D, Bellamy L, Smith N, Wintrip R. The carbon footprint of a UK University during the COVID-19 lockdown. Sci Total Environ. 2021;756:143964.

42. Remmel A. Scientists want virtual meetings to stay after the COVID pandemic. Nature. 2021;591(7849):185-6.

43. Hanaei S, Takian A, Majdzadeh R, Maboloc CR, Grossmann I, Gomes O, et al. Emerging standards and the hybrid model for organizing scientific events during and after the COVID-19 pandemic. Disaster Med Public Health Prep. 2021. https://doi.org/10. 1017/dmp.2020.406 (Epub 26 Oct 2020).

44. Choice with Responsibility: Reimagining how we work. Novartis Press Release. 2020. https://www.novartis.com/news/choice-respo nsibility-reimagining-how-we-work. Accessed 1 Apr 2021.

45. Hook A, Court V, Sovacool BK, Sorrell S. A systematic review of the energy and climate impacts of teleworking. Environ Res Lett. 2020;15(9):093003.

46. Shankar HM, Ewart G, Garcia E, Hicks A, Hardie W. COVID-19, climate change, and the American Thoracic Society. A shared responsibility. Ann Am Thorac Soc. 2020;17(9):1052-5. 